\title{
New Genotypes of Sweetleaf (Stevia rebaudiana Bertoni) Acclimatized and Bred at Buzau
}

\author{
Costel VÎNĂTORU ${ }^{1 *}$, Bianca MUȘAT ${ }^{1}$, Camelia BRATU ${ }^{1}$ and Georgios TSOKTOURIDIS ${ }^{2}$ \\ ${ }^{1}$ Vegetable Research and Development Station Buzău, 23 Mesteacănului St., zip code 120024, Buzău, \\ Romania \\ ${ }^{2}$ Institute of Plant Breeding \& Genetic Resources, EO Thessalonikis Poligirou, Thermi, GR-570 01, \\ Thessaloniki, GREECE \\ *corresponding author: costel_vinatoru@yahoo.com
}

BulletinUASVM Horticulture 76(2) / 2019

Print ISSN 1843-5254, Electronic ISSN 1843-5394

DOI:10.15835/buasvmcn-hort: 2019.0015

\begin{abstract}
In Romania, during the 1980s, this species was studied in addition to other sweetener plants, such as Jerusalem artichoke, sweet sorghum, sweet iris, etc. After 1996, the researches were restarted intensively at Vegetable Research and Development Station Buzau by the Breeding and Biodiversity Conservation Laboratory. A valuable germplasm collection has been made for this species and the new genotypes will be proposed for approval.
\end{abstract}

Keywords: breeding, distinct, genotype, germplasm, sweetener

\section{Introduction}

S. rebaudiana Bertoni has been known for many centuries by indigenous tribes of South America, who called it "kaa-hee" (sweet herb). South American Indians used stevia both as a sweetener and as a medicinal plant. Stevioside is the major sweetener present in leaves (Carneiro et al., 1997). Folk medicine of Paraguayan indigenous tribes recommends it particularly as a substance strengthening the heart, the circulatory system and regulating blood pressure (Marcinek et al., 2016). Stevia rebaudiana is often used by the food industry due to its steviol glycoside content, which is a suitable calorie-free sweetener (CarreraLanestosa et al., 2017). In 1990, Ovidio Rebaudi was the first chemist to study the chemical characteristics of the substances extracted. Its name was later changed to the current one, and it was recommended not only for food production, but also for the medicinal effects that were attributed to it (Yadav et al., 2011).
Aims: Obtaining genotypes with distinct phenotypic expression, adapted to the pedoclimatic conditions of our country and their expansion as crop vegetable.

\section{Materials and Methods}

Research began with the creation of a rich germplasm collection followed by its evaluation and the valuable genotypes were intensively bred resulting two genotypes with distinct phenotypic features. The selection method used was repeated individual selection, with particular attention being paid to genotypes that demonstrated increased resistance at low temperatures. To highlight this feature, the experience was set up in two culture environments, both greenhouse and field. Sowing has been made on March 10, and the plants sprouted on April 5 in both experimental variants. Their planting took place on May 15th. The flowering in the greenhouse took place on August 15 and in field much later, on September 
Table 1. Main features of new obtained genotypes - mean values for both greenhouse and field

\begin{tabular}{|c|c|c|c|c|c|c|c|c|c|}
\hline 1 & Culture system & \multicolumn{2}{|c|}{ Greenhouse } & \multicolumn{2}{|c|}{ Field } & \multicolumn{2}{|c|}{ G1 } & \multicolumn{2}{|c|}{$\mathrm{G} 2$} \\
\hline 2 & Cultivated genotype & G1 & G2 & G1 & $\mathrm{G} 2$ & S \% & $\mathrm{X}$ & S \% & $\mathrm{X}$ \\
\hline 3 & Plant height $(\mathrm{cm})$ & 180 & 150 & 72 & 55 & 54 & 126 & 47,5 & 102,5 \\
\hline 4 & Bush diameter $(\mathrm{cm})$ & 68 & 82 & 32 & 43 & 18 & 50 & 19,5 & 62,5 \\
\hline 5 & Main shoots no. (pieces) & 20 & 22 & 24 & 26 & 2 & 22 & 2 & 24 \\
\hline 6 & Secondary shoots no. (pieces) & 156 & 224 & 72 & 144 & 42 & 114 & 40 & 184 \\
\hline 7 & Main shoots length $(\mathrm{cm})$ & 120 & 80 & 48 & 34 & 36 & 84 & 23 & 57 \\
\hline 8 & Secondary shoots length $(\mathrm{cm})$ & 56 & 42 & 12 & 7 & 22 & 34 & 17,5 & 24,5 \\
\hline 9 & Stem thickness at the base $(\mathrm{mm})$ & 9.2 & 9.6 & 9.8 & 11.2 & 0,3 & 9,5 & 0,8 & 10,4 \\
\hline 10 & Stem length $(\mathrm{cm})$ & 5 & 3 & 4 & 3 & 0,5 & 4,5 & 0 & 3 \\
\hline 11 & Main shoots thickness (mm) & 5.1 & 5.3 & 4.4 & 4.8 & 0,35 & 4,75 & 0,25 & 5,05 \\
\hline 12 & Secondary shoots thickness (mm) & 1.4 & 1.8 & 1.9 & 2.3 & 0,25 & 1,65 & 0,25 & 2,05 \\
\hline 13 & Main shoots weight $(\mathrm{g})$ & 65 & 62 & 33 & 32 & 16 & 49 & 15 & 47 \\
\hline 14 & Secondary shoots weight (g) & 5.2 & 4.8 & 20.8 & 27 & 7,8 & 13 & 11,1 & 15,9 \\
\hline 15 & Plant weight $(\mathrm{g})$ & 1300 & 1364 & 792 & 832 & 254 & 1046 & 266 & 1098 \\
\hline 16 & Internodes distance $(\mathrm{cm})$ & 3.5 & 3.3 & 2.2 & 1.6 & 0,65 & 2,85 & 0,85 & 2,45 \\
\hline 17 & Leaf weight $(\mathrm{g})$ & 732 & 812 & 414 & 462 & 159 & 573 & 175 & 637 \\
\hline 18 & Leaf length $(\mathrm{cm})$ & 9.6 & 7.5 & 5.1 & 3.8 & 2,25 & 7,35 & 1,85 & 5,65 \\
\hline 19 & Leaf width $(\mathrm{cm})$ & 2.2 & 4.2 & 1.7 & 2.1 & 0,25 & 1,95 & 1,05 & 3,15 \\
\hline 20 & Petiole length (mm) & 8 & 5 & 5 & 4 & 1,5 & 6,5 & 0,5 & 4,5 \\
\hline
\end{tabular}

5. The seed production in greenhouse conditions took place much earlier compared to field, on September 10, opposed to the field plants that yielded after October 10. The planting scheme was $70 \mathrm{~cm}$ between rows and $30 \mathrm{~cm}$ between plants per row in the field and for greenhouse the crop was set up in tapes, at $70 \mathrm{~cm}$ between rows, $40 \mathrm{~cm}$ between plants per row and $1.2 \mathrm{~m}$ between tapes.

\section{Results and discussion}

The two genotypes have distinct phenotypic characteristics and exhibit high resistance to low temperatures. G1 (genotype 1) shows lanceolate leaves, pubescent stems and erect habit and G2 (genotype 2) shows smaller leaves, slightly ovoid, and the plant has thin branches and globular habit. The foliage is smoother and darker (Tab. 1).

In both greenhouse and field conditions, G1 recorded higher values in terms of plant height compared to G2 and in terms of plant weight, production of shoots and leaves, both in the field and in protected spaces, G2 was superior. It should be noted that yield can be doubled and even tripled if the young seedlings are harvested periodically. In protected areas the harvesting can be done 3-4 times on the vegetation cycle and 2-3 times in the field. Of all the analysed features, there was a significant decrease of the values in the field compared to greenhouse. Regarding the difference between genotypes, it is insignificant for most of the studied characters, the main distinction element being the leaf shape.

\section{Conclusion}

The researches have been completed so far with obtaining two genotypes with distinct phenotypic expressivity that can be cultivated in our country, in protected areas and field. At the same time, a valuable germplasm collection has been made for this species and a database that can assist in future breeding works. The new genotypes will be proposed for approval and can be successfully cultivated as a perennial and as an annual plant, in colder areas, with protection over winter.

\section{References}

1. Carrera-Lanestosa A, Moguel-Ordóñez Y, SeguraCampos M (2017). Stevia rebaudiana Bertoni: A Natural Alternative for Treating Diseases Associated with Metabolic Syndrome. Journal of medicinal food, 20(10): 933-943.

2. Carneiro JWP, Muniz AS, Guedes, TA (1997). Greenhouse bedding plant production of Stevia rebaudiana (Bert) Bertoni. Canadian Journal of Plant Science, 77(3): 473474.

3. Marcinek K, Krejpcio Z (2016). Stevia rebaudiana Bertoni: health promoting properties and therapeutic applications, J. Verbr. Lebensm, 11(1): 3-8.

4. Yadav AK, Singh S, Dhyani D, Ahuja PS (2011). A review on the improvement of stevia [Stevia rebaudiana (Bertoni)]. Canadian Journal of Plant Science, 91(1): 1-27. 